\title{
Speed of oral and written responding
}

\author{
SLATER E. NEWMAN \\ North Carolina State University, Raleigh, North Carolina 27607 \\ and \\ LAWRENCE R. NICHOLSON \\ Campbell College, Buies Creek, North Carolina 27506
}

\begin{abstract}
Subjects were given three trials to speak and to write as fast as they could both the alphabet and a set of two-digit numbers. The speed of oral responding was approximately six syllables per second for letters and seven syllables per second for digits. The speed for writing was approximately two items per second for both digits and letters. Correlations between tasks within the same mode were all significant $(p<.01)$; correlations between modes on the same task were usually not. Implications for research in verbal learning and memory are discussed.
\end{abstract}

In research on verbal learning and memory, responses are usually oral or written. A number of experiments have provided information about the maximum speed of these responses. For oral responses, average speeds of five to eight syllables per second have been reported when instructions have been to say the alphabet as fast as possible (Landauer, 1962; Weber \& Bach, 1969; Weber \& Castleman, 1970; Weber, Kelly, \& Little, 1972), and approximately 10 syllables per second when instructions have been to speak aloud two-digit numbers as quickly as possible (Landauer, 1962). In addition, Landauer (1962), Weber and Bach (1969) and Weber and Castleman (1970) have all demonstrated that saying the alphabet to oneself occurs no faster than saying it aloud. Results such as these have been used to estimate the rate at which subjects are able to process information (cf. Neisser, 1967, p. 43; Posner, 1974, p. 112; Sperling, 1967, p. 287).

Information about the rate of written responding has been reported by Provins and Glencross (1968) and by Weber, Kelley, and Little (1972). Both experiments showed that when subjects were instructed to write the alphabet as fast as possible, an average speed of approximately two items per second was attained.

In the present study, we obtained data for each subject for both written and oral responding on the alphabet and on a set of two-digit numbers (viz.

This research was supported by the National Science Foundation under Grant GB-6044. The paper was prepared by the senior author during tenure of an Honorary Research Fellowship at Birkbeck College, University of London. We appreciate discussion with and comments by George Allen, Margaret Cooper, Jeffrey Frederick, Michael Goodman, David Legge, Mary McGraw, and Donald Mershon. Requests for reprints should be sent to Slater E. Newman, Department of Psychology, North Carolina State University, Raleigh, North Carolina 27607.
31-60). This enabled us to compare directly, as did Weber, Kelley, and Little (1970), the speed of responding in the two modes and to determine both the extent to which performance in one mode is related to performance in the other and the relationship between performance on the two tasks within the same mode. Three trials were given on each task in each response mode.

\section{METHOD}

\section{Subjects and Design}

The subjects were 26 male undergraduates enrolled in the introductory psychology course at North Carolina State University. For 14 subjects (Group W), the written mode was first on each task and for 12 subjects (Group 0 ), the oral mode was first. For all subjects, the alphabet task preceded the digit task. Data are not included for six additional subjects who did not follow instructions (e.g., who omitted or added items) or who did not used the same writing style (i.e., lowercase print or script) on all trials.

\section{Procedure}

Subjects were run individually. Each was given three trials to produce the alphabet, and then the digits $31-60$ as fast as he could. There were intervals of $10 \mathrm{sec}$ between trials on each task, about $30 \mathrm{sec}$ when modes within a task were changed, and about $30 \mathrm{sec}$ when tasks were changed. The oral responses were tape-recorded.

For the written mode, each subject was instructed to produce the alphabet (either in print or script) on a single line using lowercase letters and to produce the digit pairs in a column from top to bottom, one two-digit number per line. A stopwatch was used to record the time to the nearest $.1 \mathrm{sec}$.

\section{RESULTS}

Half of the subjects (five in Group W and eight in Group 0) wrote the alphabet in script and half (nine in Group W and four in Group 0) printed it. Since there were no differences in performance within a response mode for these subjects, their data have been combined. Table 1 presents the mean and standard deviation for each group on each trial.

These data show that for both groups, the mean 
Table 1

Speed (in Seconds) of Oral and Written Responding on Each Trial

\begin{tabular}{|c|c|c|c|c|c|c|c|c|c|c|c|c|c|}
\hline & & & & Alph & & & & & & & & & \\
\hline & & & tten $\mathrm{T}$ & & & al Tri & & & tten $T$ & & & ral Tria & \\
\hline Grou & & 1 & 2 & 3 & 1 & 2 & 3 & 1 & 2 & 3 & 1 & 2 & 3 \\
\hline W & $\begin{array}{l}\text { Mean } \\
\text { SD }\end{array}$ & $\begin{array}{c}14.8 \\
2.80\end{array}$ & $\begin{array}{c}13.3 \\
1.54\end{array}$ & $\begin{array}{c}12.7 \\
1.45\end{array}$ & $\begin{array}{l}5.3 \\
1.21\end{array}$ & $\begin{array}{l}4.9 \\
1.07\end{array}$ & $\begin{array}{l}4.8 \\
1.15\end{array}$ & $\begin{array}{c}29.4 \\
2.06\end{array}$ & $\begin{array}{r}28.7 \\
2.31\end{array}$ & $\begin{array}{c}28.8 \\
2.52\end{array}$ & $\begin{array}{c}13.0 \\
2.14\end{array}$ & $\begin{array}{c}13.1 \\
1.89\end{array}$ & $\begin{array}{c}12.6 \\
1.67\end{array}$ \\
\hline 0 & $\begin{array}{l}\text { Mean } \\
\text { SD }\end{array}$ & $\begin{array}{c}15.8 \\
3.23\end{array}$ & $\begin{array}{c}14.0 \\
1.72\end{array}$ & $\begin{array}{c}13.4 \\
1.45\end{array}$ & $\begin{array}{l}5.8 \\
1.54\end{array}$ & $\begin{array}{l}5.2 \\
1.06\end{array}$ & $\begin{array}{l}5.0 \\
1.04\end{array}$ & $\begin{array}{c}30.9 \\
4.67\end{array}$ & $\begin{array}{c}30.8 \\
5.38\end{array}$ & $\begin{array}{c}30.7 \\
4.88\end{array}$ & $\begin{array}{c}12.9 \\
1.53\end{array}$ & $\begin{array}{c}12.6 \\
1.30\end{array}$ & $\begin{array}{c}12.6 \\
1.46\end{array}$ \\
\hline
\end{tabular}

*See text for explanation.

speaking speed on the third trial (usually the fastest) was approximately six syllables per second for the alphabet and approximately seven syllables per second for digits. The writing speed on the third trial for both groups was approximately two items per second with letters and with digits. For each subject on each task, the speaking rate was faster than the writing rate.

To study the relationship between performance on the two tasks within each mode, as well as performance between modes within each task, rank-order correlations were done for each group. For each subject, the fastest of his three trials on each task-mode combination was used. Data for all subjects within a group were used in determining the correlations for the group.

For each group, the correlation between tasks within each mode were all significant $(\mathrm{p}<.01)$. For Group $\mathrm{W}$, the correlation for written responding was .691 and for oral responding .770; for Group 0, the corresponding values were .811 and .787 . The relationship between response modes within subjects was substantially lower. For Group W, the correlation on the alphabet task was .094 and on the digit task -.015 , whereas for Group 0 , the comparable values were .459 and .727 . Only the last is significant $(\mathrm{p}<.01)$.

\section{DISCUSSION}

The results of this experiment combined with those of Provins and Glencross (1968) and of Weber, Kelley, and Little (1972) indicate that the writing speed for the alphabet and for digits is approximately two items per second. Faster speeds for digits might have been obtained in this experiment, had subjects been permitted to write more than two digits on a line. Faster speeds may also have been obtained for letters, had highly familiar words been used, since their letter sequences may have been easier to produce than some of those of the alphabet.

The speaking speed for letters obtained in this experiment falls within the range of those obtained in other experiments (i.e., five to eight syllables per second). For digits, however, the speed (i.e., seven syllables per second) is somewhat less than the 10 syllables per second reported for Landauer's typical subject.

In both this and Landauer's experiment, oral performance was somewhat faster on digits than on the alphabet. The greater speed for digits could derive from greater repetition on the digit task (e.g. . in counting from 40 to 49 , "forty" is spoken 10 times), and perhaps concomitantly longer sequences between pauses than on the alphabet task. We have no suggestions other than possible population differences to account for the differences in speed between experiments either for letters or for digits.

The significant correlations between tasks for each mode suggest that speaking speed and writing speed are each relatively stable. The remaining correlations suggest, however, that speed of writing and speed of speaking may be relatively independent of one another.

The procedure and the results of this study appear to have implication for research on memory, particularly where responses are paced. The information about writing speed could prove useful in deciding on the time to allow on tasks requiring written responding and in interpreting the results of experiments using such tasks. For example, in a free recall experiment (Shapiro \& Ponce, 1970), some subjects were paced at a 2 -sec rate during the written recall tests. Since the words on the list varied from 4 to 10 letters, the results of the present experiment suggest that some of their subjects may have had difficulty completing the longer words during the $2-\mathrm{sec}$ interval. The same may have been true for some of the subjects in the experiment of McCullers and Haller (1972) in which list items varied in length from three to nine letters. ${ }^{1}$

It may be desirable to use a procedure like that described here to obtain information about how long it takes to write or speak the items to be chosen for a particular experiment. For example, when several lists are to be used in the same experiment, whether within or between treatments, the time to speak or write each list might be obtained and its relationship to the major dependent variables might then be determined. It is possible that response speed would be a useful measure for matching lists to be used in an experiment. or in helping explain the results of an experiment in which the list for one treatment took longer to produce than the list for another treatment (cf. Newman \& Williams, 1967).

A final suggestion derives from the positive correlations observed between the two tasks within each response mode. If response speed is found to be related to performance on a particular task, it might be desirable to assign subjects to treatments in experiments in which that task is to be used, on the basis of their response speed in the mode to be used in the experiment. Study of the relationship between response speed for each mode and performance on various experimental tasks in which that mode is to be used seems indicated.

\section{REFERENCES}

Landauer, T. K. Rate of implicit speech. Perceptual and Motor Skills. 1962, 15, 646.

McCullers, J. C., \& Haller, J. Another look at paced versus unpaced recall in free learning. Journal of Experimental Psychology, 1972, 92, 439-440.

Neisser, U. Cognitive Psychology. New York: AppletonCentury-Crofts, 1967.

Newman, S. E., \& Williams, C. M. Response speed for easy- and 


\section{NEWMAN AND NICHOLSON}

hard-to-pronounce trigrams. Journal of Verbal Learning and Verbal Behavior, 1967, 6, 661-667.

Posner, M. I. Cognition: An introduction. Glenview, Ill: Scott-Foresman, 1974.

Provins, K. A., \& Glencross, D. J. Handwriting, typewriting, and handedness. Quarterly Journal of Experimental Psychology, $1968,20,282-289$.

Shapiro, S. I., \& Ponce, I. Free recall and organization as functions of paced or unpaced responding and presentation rate. Psychonomic Science, 1970, 18, 329-330.

Sperling, G. A. Successive approximations to a model for short-term memory. Acta Psychologica, 1967, 27, 285-292.

WEBER, R. J., \& BACH, M. Visual and speech imagery. British Journal of Psychology, 1969, 60, 199-202.
Weber, R. J., \& Castleman, J. The time it takes to imagine. Perception and Psychophysics, 1970, 8, 165-168.

Weber, R. J., Kelley, J., \& LitTle, S. Is visual image sequencing under verbal control? Journal of Experimental Psychology, 1972, 96, 354-362.

\section{NOTE}

1. Differences between items in production time may be used by subjects as a basis for deciding both on the order in which items are to be learned and on the order the items are to be produced on test trials.

(Received for publication November 3, 1975.) 